\title{
Increase in clusterin forms part of the stress response in Hodgkin's lymphoma
}

\author{
RAFFAELE FRAZZI ${ }^{1,2}$, BRUNO CASALI ${ }^{2}$, MAURO IORI $^{3}$, DAVIDE NICOLI $^{2}$, \\ CATERINA MAMMI $^{1}$ and FRANCESCO MERLI ${ }^{1}$ \\ ${ }^{1}$ Hematology Division, ${ }^{2}$ Molecular Biology Laboratory and ${ }^{3}$ Medical Physics Division, \\ Azienda Ospedaliera S. Maria Nuova, Viale Risorgimento 80, Reggio Emilia, Italy
}

Received October 11, 2010; Accepted December 1, 2010

DOI: $10.3892 /$ ijo.2011.907

\begin{abstract}
Clusterin (also called APOJ, SGP-2, XIP8) has thus far been only partially characterized in lymphomas contrary to other types of cancer. Its expression has been reported only for anaplastic large cell lymphomas and, more recently, in mycosis fungoides. Here, we demonstrate an upregulation of intracellular clusterin in Hodgkin's lymphoma (HL)-derived cell lines L-428, KM-H2 and L-540, caused by different stimuli such as IFN- $\gamma$, doxorubicin and $\mathrm{X}$-rays. These stimuli are relevant for the pathophysiology and therapy of HL and represent a first step in the characterisation of this glycoprotein known to have a role in drug chemoresistance. p53 up-regulation accompanies increases in clusterin levels accordingly with the onset of apoptosis. We also show that the cells secrete more clusterin after treatment with doxorubicin, which is consistent with the observed intracellular increase. These observations suggested that the levels of circulating clusterin should also be measured in the peripheral blood from HL patients both at the time of diagnosis and after two cycles of chemotherapy. In a preliminary study on patient sera we observed that an increase in clusterin is correlated with positron emission tomography (PET) positivity after two cycles of chemotherapy.
\end{abstract}

\section{Introduction}

Hodgkin's lymphoma (HL) is a neoplasm of the lymph nodes originating from the germinal center (GC) B lymphocytes. It has an incidence rate of $13 \%$ in the United States and includes two major hystotypes: nodular sclerosis and mixed cellularity $(1,2)$. These, together with lymphocyte-rich and lymphocyte-depleted HL are collectively referred as classical Hodgkin's lymphoma (cHL) (3). cHL represents a peculiar

Correspondence to: Dr Francesco Merli, Hematology Division, Azienda Ospedaliera S. Maria Nuova, Reggio Emilia, Italy

E-mail: francesco.merli@asmn.re.it

Key words: Hodgkin's lymphoma, clusterin, doxorubicin, apoptosis, positron emission tomography example of a neoplasm characterised by the presence of the malignant Reed-Sternberg cells (HRS cells). These cells are rare, accounting for $\sim 1-5 \%$ of the cells in affected lymph nodes, and are surrounded by benign cells including $\mathrm{T}$ lymphocytes, B lymphocytes, macrophages, eosinophils, plasma cells and fibroblasts $(3,4)$. The majority of the tumor mass is therefore made up of this inflammatory infiltrate (3). Although combined modality treatments, including ABVD chemotherapy (doxorubicin, bleomycin, vinblastine and dacarbazine) and radiotherapy, now allow significant achievements particularly in early stages, therapy-resistance, relapsing disease and late toxicities require great efforts to be put into chemo- and radiotherapy optimization (5-7). Moreover, since HL patients are often adolescents and young adults, the risk of sterilization associated with chemotherapy is another issue to take into account (8). Our aim is therefore to identify relevant putative biomarkers able to correlate with the response of the tumor to cytotoxic drugs or radiation therapy, and to add significant information to the prognostic procedures for HL currently in use.

Clusterin (also called APOJ, SGP-2, XIP8) is a heterodimeric, disulphide-linked glycoprotein of 449 amino acids widely expressed in human tissues and implicated in several cell functions including tumor progression, cell adhesion, tissue remodelling, lipid metabolism, apoptosis and DNA repair $(9,10)$. The nuclear isoform (nCLU) is pro-apoptotic and is specifically involved in the drug-mediated apoptosis of prostate cancer cells, whereas the secretory isoform (sCLU) is believed to have a cytoprotective role $(11,12)$. This protein has also been found to be associated with several different malignancies such as colon $(13,14)$, breast $(15,16)$ and lung carcinomas $(17,18)$ making it not only a basic research subject but also a potential therapeutic target for prostate cancer $(19,20)$.

Only limited evidence is available concerning the role of clusterin in lymphomas, however. This protein has been described as a marker for only anaplastic large-cell lymphoma and mycosis fungoides, while many of the lymphoid cell lines tested so far resulted negative for clusterin expression (21-23). Even though this protein has a wide distribution among human tissues and fluids, HL's immunohistochemical stainings have been reported to be negative (21). 
It is known that the evasion mechanisms of HRS cells include the presence of regulatory $\mathrm{T}$ cells (Treg) among the HL-infiltrating lymphocytes. Significant amounts of CD4+CD25 $5^{+}$Treg and IL-10 secreting T-regulatory 1 have been found in HL-infiltrating lymphocytes and are believed to be responsible for the immunosuppressive environment characteristic of HL (24). Furthermore, cytokines have always been regarded as crucial players in HL pathogenesis, with HL patients being characterised by a lower $\mathrm{T}$ helper-1 cytokine activity, a T helper-2/Treg-skewed type of immunity and a lower level of peripheral blood IL-12 $(3,25)$. This is consistent with recent evidence, which has stressed the importance of $\mathrm{CD}^{+}{ }^{+}$-secreted interferon- $\gamma(\mathrm{IFN}-\gamma)$ during T-lymphocyte mediated responses and pathogenesis control of HL. This cytokine is specifically secreted by HLinfiltrating $\mathrm{CD}^{+} \mathrm{T}$ lymphocytes upon blocking the inhibitory PD-1-PD-Ls interaction in bulk tumour cell suspensions (26).

The experiments described in this work are aimed at evaluating the expression and the modulation of intracellular and secretory clusterin in the HL-derived cell lines L-428, KM-H2 and L-540, where clusterin had never been reported before. We show that intracellular clusterin expression is dramatically affected by different stimuli such as doxorubicin (a chemotherapeutic drug belonging to the ABVD combination therapy), IFN- $\gamma$ (a Th-1 cytokine) and X-rays. We also show that clusterin secretion increases following treatment with doxorubicin. In order to evaluate the potential of this secreted glycoprotein as biomarker able to provide information on the progression of $\mathrm{HL}$, we performed a preliminary study on sera of HL patient who had undergone two cycles of doxorubicin-containing chemotherapy followed by positron emission tomography (PET) scan. Collection of sera was approved by the Ethics committee of Azienda Ospedaliera S. Maria Nuova.

\section{Materials and methods}

Cell lines and growth conditions. L-428, KM-H2 and L-540 Hodgkin's lymphoma-derived cell lines were purchased from the DSMZ German collection of microorganisms and cell cultures (Braunschweig, Germany). RPMI medium (Euroclone, Milan, Italy) supplemented with penicillin/ streptomycin (Euroclone), L-glutamine (Euroclone) and 10\% heat-inactivated foetal calf serum (FCS, Gibco-Invitrogen, San Giuliano Milanese, Italy) was used to grow L-428 and KM-H2. L-540 required $20 \%$ foetal calf serum. Cells were grown in a humidified incubator at $37^{\circ} \mathrm{C}$ with a $5 \% \mathrm{CO}_{2}$ atmosphere.

Doxorubicin and IFN- $\gamma$. Doxorubicin hydrochloride (SigmaAldrich) was dissolved in sterile water at a concentration of $10 \mathrm{mM}$ and stored at $-20^{\circ} \mathrm{C}$. A $1 \mathrm{mM}$ stock solution was prepared and stored at $4^{\circ} \mathrm{C}$. Human recombinant IFN- $\gamma$ (Peprotech, Rocky Hill, NJ) was dissolved in sterile phosphatebuffered saline (PBS) $1 \mathrm{X}$ pH 7.2 supplemented with $0.1 \%$ bovine serum albumine (Sigma-Aldrich) at a concentration of $1 \mathrm{mg} / \mathrm{ml}$ and stored in aliquots at $-20^{\circ} \mathrm{C}$.

Flow cytometry. Cells $\left(1.8 \times 10^{5}\right)$ were washed with PBS $1 \mathrm{X}$ pH 7.2 and stained with FITC-conjugated anti-IFNGR1 monoclonal antibody (Genetex, Irvine, CA) diluted 1:250. Following another wash, control and stained samples were acquired through a Cytomics FC500 flow cytometer (Beckman Coulter Inc., Fullerton, CA).

$X$-ray irradiation. Raycell blood irradiator (MDS Nordion, Ottawa ON, Canada) was chosen to deliver X-rays to cell lines by using two opposite X-ray tubes with a potential of $160 \mathrm{kV}$. A mean dose $( \pm 1 \sigma)$ of $12.00 \pm 0.24 \mathrm{~Gy}$ in $1 \mathrm{~min}$ and $53 \mathrm{sec}$ of beam-on time were delivered to each cell flask placed in the dedicated irradiation canister. To limit the nonuniform dose-effect in the inner area of the irradiation field, an in-house made plastic holder was used to arrange the flasks in the same position inside the canister for the different irradiations. Besides, to obtain the maximum dose uniformity the canisters were always filled with water. Cells were counted on a haemocytometer and $1.5 \times 10^{6}$ cells/sample were seeded in a $25-\mathrm{cm}^{2}$ flask (Euroclone). The flask was then filled with fresh culture medium (RPMI medium with $10 \%$ FCS) up to the top, in order to avoid the lack of homogeneity due to air bubbles. After irradiation the whole flask content was centrifuged, the liquid discarded and the cells resuspendend in fresh culture medium. Cells were counted again and an equal number of irradiated cells was seeded as well as a control sample. Flasks were incubated in a $37^{\circ} \mathrm{C}$ humidified incubator with $5 \% \mathrm{CO}_{2}$ atmosphere for 24,48 or $72 \mathrm{~h}$.

Antibodies and immunoblotting. The total cell extracts were prepared as follows. Cells were centrifuged (1100 rpm for $6 \mathrm{~min})$ and the supernatant discarded. The samples were washed twice with PBS 1X pH 7.2 and, after centrifugation, the buffer was removed carefully. Cells were resuspended in

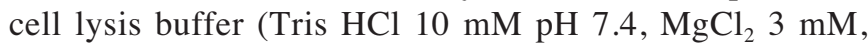
$\mathrm{NaCl} 10 \mathrm{mM}$, SDS $0.1 \%$, Triton $0.1 \%$ and EDTA $0.5 \mathrm{mM}$ ) supplemented with protease inhibitor cocktail for general use (Sigma-Aldrich). Cell lysis was accomplished through pipetting and incubating at $4^{\circ} \mathrm{C}$ for 40 min with shaking. Samples were stored at $-20^{\circ} \mathrm{C} \mathrm{O} / \mathrm{N}$ and centrifuged, the day after, at $13000 \mathrm{rpm}$ and $4^{\circ} \mathrm{C}$ for $20 \mathrm{~min}$. The cell lysate was then quantified by Bio-Rad Dc Protein assay (Bio-Rad, Segrate, Milan, Italy), aliquoted and stored at $-20^{\circ} \mathrm{C}$ until use. SDS-PAGE electrophoresis was performed on $10 \%$ polyacrylamide gels, which were either hand-made or precast and proteins were blotted on Hybond-ECL or Hybond-C plus nitrocellulose membrane (GE Amersham, Milan, Italy). Monoclonal antibodies (mAbs): mouse anti-p53 mAb (clone PAB1801, Zymed, San Francisco, CA) and mouse anticlusterin mAb (clone Hs-3, Biovendor, CTPark Modrice, Czech Republic) were diluted 1:2000; mouse anti-ß-actin (clone AC-15, Sigma-Aldrich) was diluted 1:24000. Rabbit anti-Bax polyclonal antibody (Immunological sciences, Rome, Italy) was diluted 1:400. Anti-mouse IgG HRP-linked and anti-rabbit IgG HRP-linked (GE Amersham) were diluted 1:10000. GE Amersham ECL detection system was used according to the manufacturer's instructions.

Nucleosomes release assay. Cell death detection ELISA plus (Roche Diagnostics $\mathrm{GmbH}$ ) was used to measure the in vitro mono- and oligonucleosomes in the cytoplasm of cells treated with IFN- $\gamma$ for $24 \mathrm{~h}$ according to the manufacturer's instructions. 
A

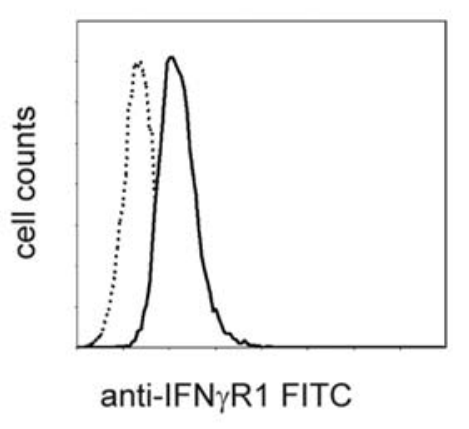

B

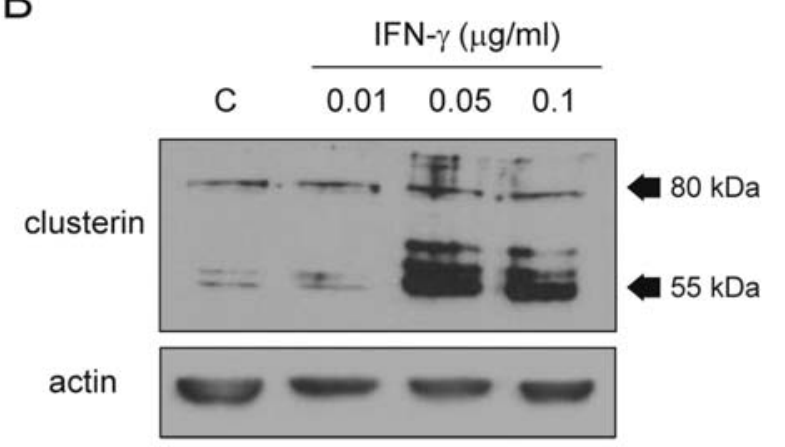

C
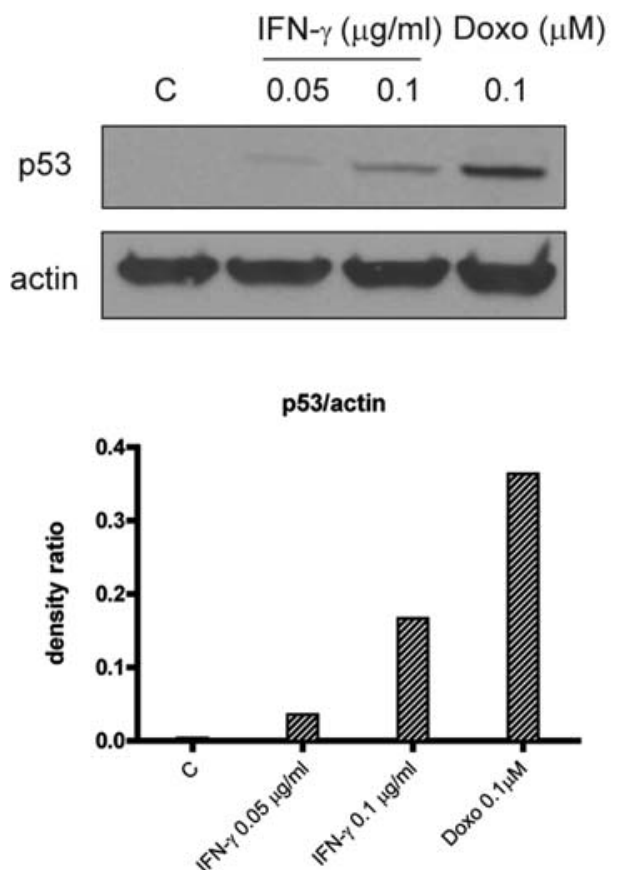

D nucleosomes release by ELISA

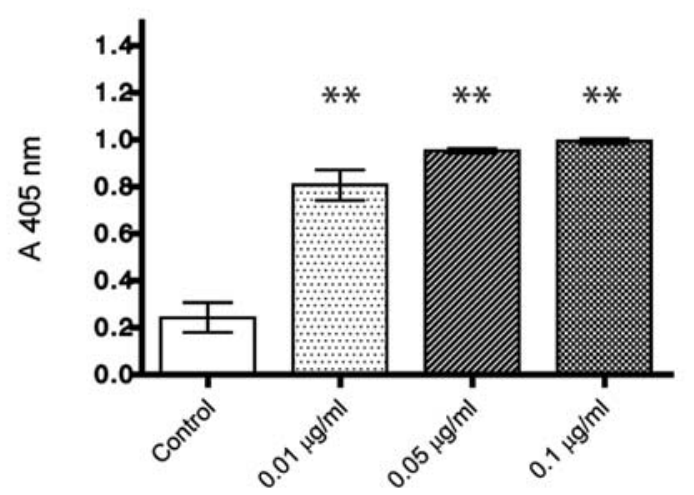

E
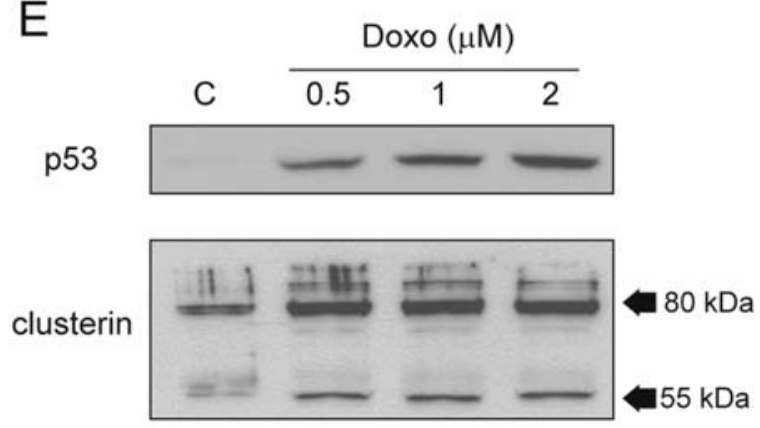

actin

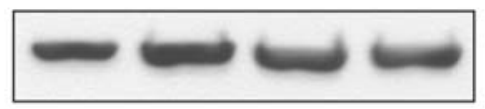

clusterin $(55 \mathrm{kDa}) /$ actin

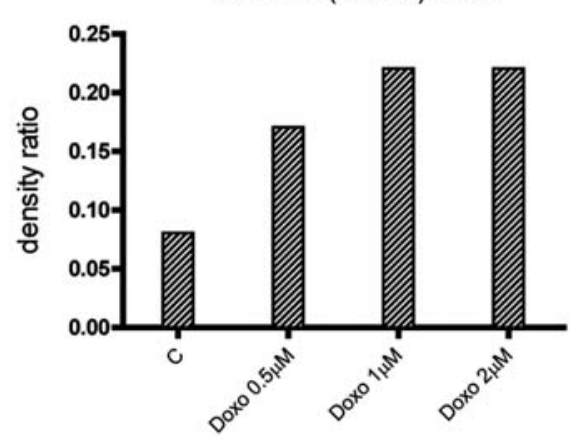

Figure 1. (A) L-428 express IFN- $\gamma$ R1. Histogram with dotted line: unstained control sample. Histogram with thick line: anti-IFN- $\gamma$ R1-FITC-stained sample. (B) IFN- $\gamma$ mediated clusterin up-regulation after $24 \mathrm{~h}$. (C) IFN- $\gamma$ mediated p53 up-regulation after $24 \mathrm{~h}$. Doxorubicin $0.1 \mu \mathrm{g} / \mathrm{ml}$ has been used as the positive control. Histograms in the lower panel show the densitometric analysis. (D) Nucleosome-release induced by IFN- $\gamma$ treatment for $24 \mathrm{~h}$. Differences are statistically significant with one-way ANOVA, ${ }^{* *} \mathrm{p}<0.001$. (E) Doxorubicin-mediated clusterin up-regulation. The lower panel shows the densitometric analysis of the 55-kDa band over actin.

Immunoenzymatic assays. Circulating clusterin was assessed on sera from samples of confirmed HL cases stored at $-80^{\circ} \mathrm{C}$. The human clusterin ELISA (Biovendor) was used according to the manufacturer's instructions with sera diluted 1:3000. Each sample was tested in duplicate. Absorbance readings (450 nm with $620 \mathrm{~nm}$ reference filter) were done with a Seac Sirio $\mathrm{S}$ multiwell plate reader.
Software and statistical analysis. Un-Scan-It software (Silk Scientific Inc., Orem, UT) was used to perform the quantification of the immunoblotting bands. Graphs and statistics for the densitometric analysis after immunoblotting, for the growth curves and for the immunoenzymatic assays were done with Graph Pad Prism 5.0 (GraphPad software Inc., La Jolla, CA). One-way ANOVA and paired t-test were 
A
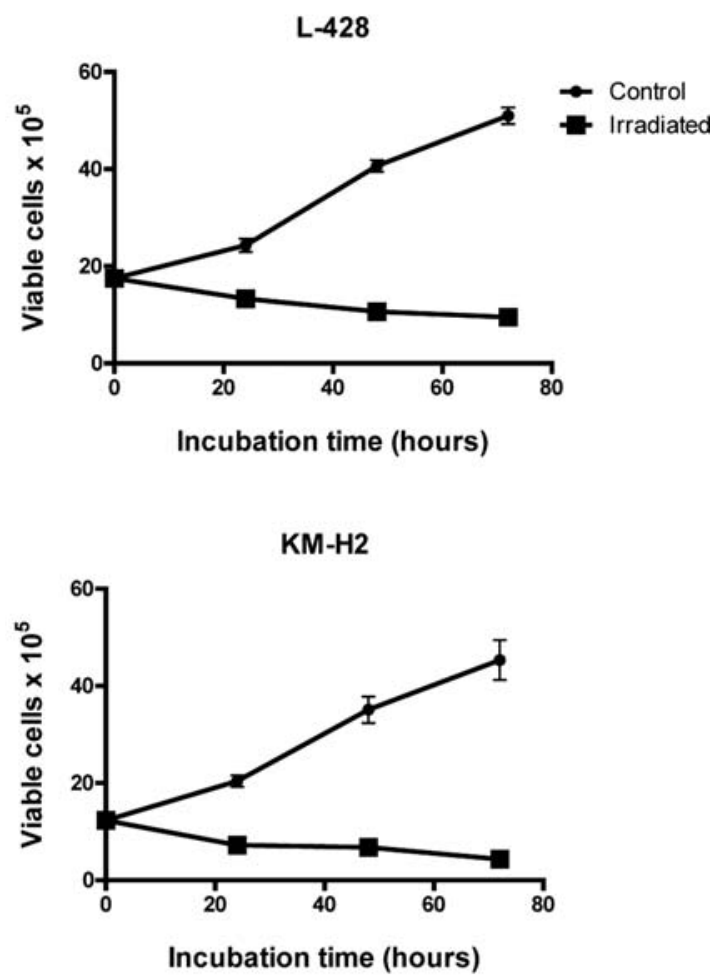

L-540

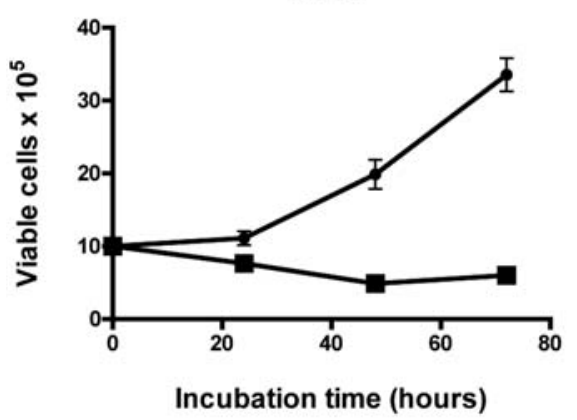

B

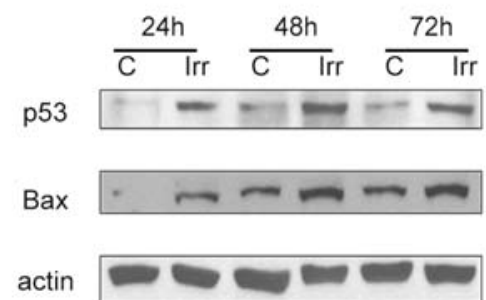

Figure 2. (A) Growth curves of HL-derived cell lines irradiated with 12-Gy $\mathrm{X}$-rays. Cells were cultured up to $72 \mathrm{~h}$ after irradiation. (B) Activation of the intrinsic apoptotic pathway after irradiation of L-428 is demonstrated by p53 and Bax up-regulation.

performed with Graph Pad Prism 5.0 as well. Flow cytometric data were analyzed through the CXP analysis software (Beckman Coulter Inc.).

\section{Results}

IFN- $\gamma$ and doxorubicin induce intracellular clusterin expression in $L-428$. We first investigated whether IFN- $\gamma$ treatment is able to induce any changes involving intracellular clusterin in L-428 cell line. These cells feature the IFN- $\gamma$ receptor, as shown in Fig. 1A. We observe a marked increase of intracellular clusterin expression in L-428 triggered by a 0.05 and $0.1 \mu \mathrm{g} / \mathrm{ml} \mathrm{IFN}-\gamma$ treatment for $24 \mathrm{~h}$. This up-regulation concerns both the major isoforms, the heavy one of $\sim 80 \mathrm{kDa}$ and the lighter one of $\sim 55 \mathrm{kDa}$ in addition to two other bands with an intermediate molecular weight (Fig. 1B). Interestingly, a dose-dependent $\mathrm{p} 53$ increase over its basal levels was evident when a treatment of $0.1 \mu \mathrm{g} / \mathrm{ml}$ was administered, starting at $0.05 \mu \mathrm{g} / \mathrm{ml}$ (Fig. 1C). In the same cells, we also investigated whether the release of nucleosomes, a marker for apoptosis, was associated to an increase in p53 and we found that IFN- $\gamma$ determines a dose-dependent increase of nucleosome-release at the same concentrations that are able to up-regulate clusterin (Fig. 1D).

Experiments were also performed with doxorubicin, a well-characterized anticancer drug belonging to the ABVD chemotherapy and acting as pro-apoptotic agent $(27,28)$ in order to compare its effects to those of IFN- $\gamma$. We observed a strong intracellular clusterin up-regulation after doxorubicin had been administered for $24 \mathrm{~h}$. This is accompanied, as expected, by an up-regulation of p53, since doxorubicin is a pro-apoptotic drug (Fig. 1E). Densitometry shows that a 2.1 -fold increase over the untreated samples of the $55-\mathrm{kDa}$ band is observed starting at $0.5 \mu \mathrm{M}$ and a 2.8 -fold increase is obtained after 1 and $2 \mu \mathrm{M}$. The average increase of the 55-kDa band is 2.4-fold in independent experiments (Fig. 1E). While IFN- $\gamma$ treatment exerts only a modest cytostatic effect, doxorubicin determines, as expected, a marked growth inhibition of L-428 at the concentrations tested (data not shown). These results show that intracellular clusterin is modulated by IFN- $\gamma$ and doxorubicin, and that $\mathrm{p} 53$ increases consistently in response to the same stimuli and concentrations. This suggests a correlation between p53 and clusterin upregulation in lymphoid cells undergoing apoptosis.

12-Gy ionizing radiation inhibits HL-cell lines and triggers the intrinsic apoptotic pathway. In order to assess the involvement of clusterin in the ionizing radiation (IR)triggered response of lymphoid cells, we tested the X-ray dose able to kill $70-80 \%$ of the cell population initially seeded. The aim was to get a population of surviving cells and to assess the intracellular clusterin levels in this population after irradiation. We irradiated the three HL cell lines and we obtained the corresponding growth curves (Fig. 2A). We show that $12 \mathrm{~Gy}$ is a suitable dose of X-rays able to inhibit the three cell lines tested leaving a population of cells that survive up to three days after irradiation. We also verified the activation of the intrinsic apoptotic pathway after irradiation in the representative L-428 cell line. p53 and Bax are upregulated in the irradiated, surviving population up to $72 \mathrm{~h}$ (Fig. 2B), which is consistent with the fact that high doses of IR generate single- and double-strand DNA breaks.

Cells that survive after irradiation feature higher intracellular clusterin. A strong increase of intracellular clusterin is evident after irradiation at the three time points studied in all the HL cell lines tested (Fig. 3), which is consistent with the data previously reported for breast carcinoma (15). The 

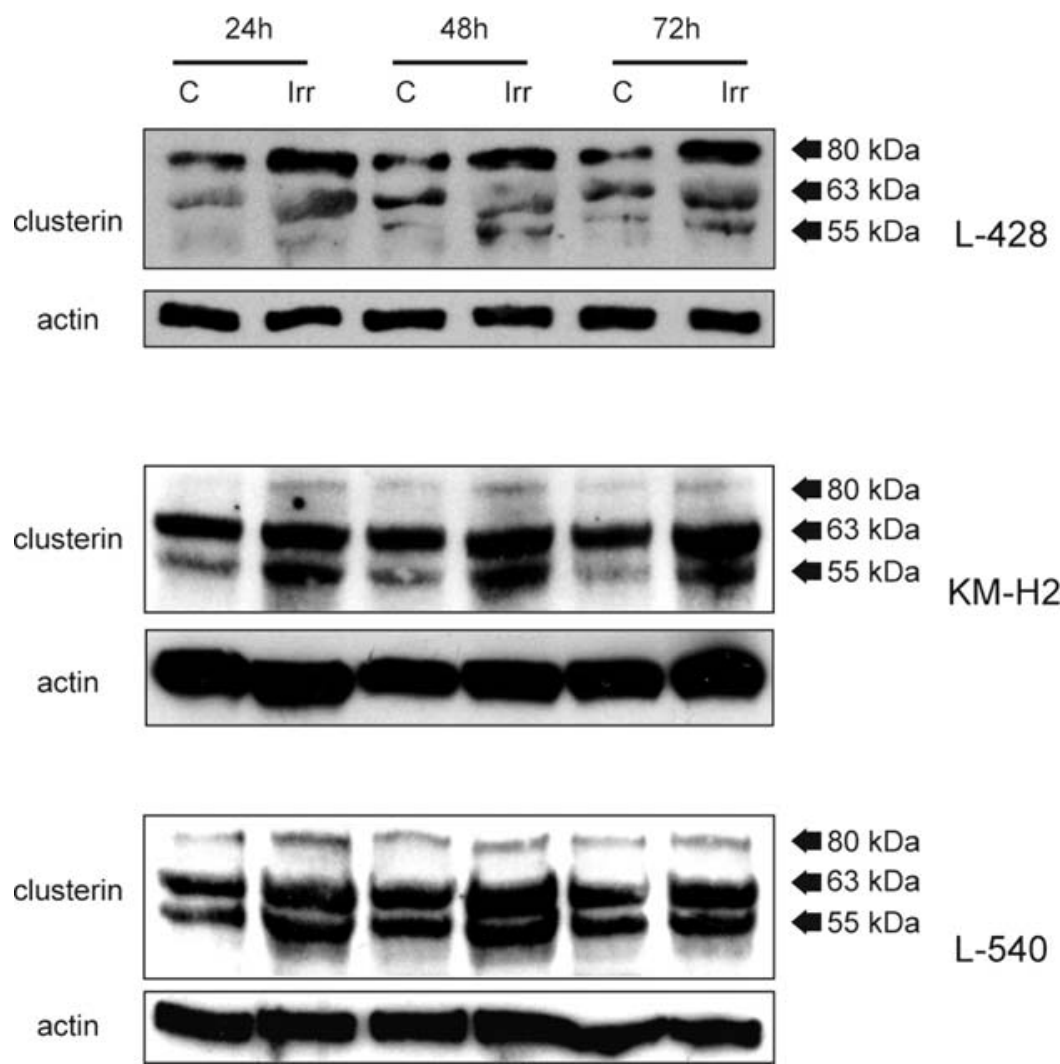

Figure 3. Clusterin is up-regulated by IR in HL-derived cell lines. The increase of the intracellular isoforms of 80,63 and $55 \mathrm{kDa}$ is evident in the three cell lines tested up to $72 \mathrm{~h}$. (A) L-428; (B) KM-H2; (C) L-540. Results are representative of 2-3 independent experiments in each cell line.

Table I. Circulating clusterin in HL patients. ${ }^{\mathrm{a}}$

\begin{tabular}{lcccc}
\hline & No. of patients & Decreased clusterin levels & Increased clusterin levels & Steady clusterin levels \\
\hline PET2- & 9 & $5 / 9(55.6 \%)$ & $0 / 9$ & $4 / 9(44.4 \%)$ \\
PET2 $^{+}$ & 9 & $0 / 9$ & $7 / 9(77.8 \%)$ & $2 / 9(22.2 \%)$ \\
\hline
\end{tabular}

aSera from 18 confirmed cases of HL were assessed at the time of diagnosis and after two cycles of doxorubicin-containing chemotherapy followed by PET scan.

increase in clusterin and the p53 up-regulation shown in Fig. 2B happen simultaneously after irradiation. Therefore, higher clusterin is a feature of cells that survive X-rays in lymphoid cells as well and may represent a resistance mechanism triggered by the injured cell, according to a cytoprotective role postulated for this protein (34). Collectively, the data presented so far show that clusterin up-regulation in HL cell lines is triggered by doxorubicin, IFN- $\gamma$ and high doses IR, which occur simultaneously with p53 up-regulation.

Doxorubicin up-regulates sCLU in a dose-dependent fashion. We next investigated whether increasing doses of doxorubicin had any effect on clusterin secretion. We observed a dose-dependent increase of the secretory, highly glycosylated isoforms after $24 \mathrm{~h}$ treatment in the supernatant of the three cell lines L-428, KM-H2 and L-540 (Fig. 4). The molecular weights of the two bands of sCLU are different from the intracellular ones and reflect the glycosylation of the secreted protein. This result is consistent with the observed increase of the intracellular isoforms shown in Fig. 1E with the same drug concentrations. We therefore hypothesize that, also in vivo, the HRS cells of the tumoral mass may contribute to the levels of circulating clusterin under physiological conditions and that secretion is affected by chemotherapeutic treatment with doxorubicin in HL patients.

Circulating clusterin in HL patients. The data presented so far prompted us to investigate circulating clusterin in the peripheral blood from HL patients. Here we describe a preliminary study carried out on 18 sera from confirmed HL cases who had undergone PET for diagnostic and prognostic purposes. It has, in fact, been demonstrated that PET after two cycles of ABVD chemotherapy (PET2) is an excellent prognostic parameter for oncohematologists (30). PET2- 


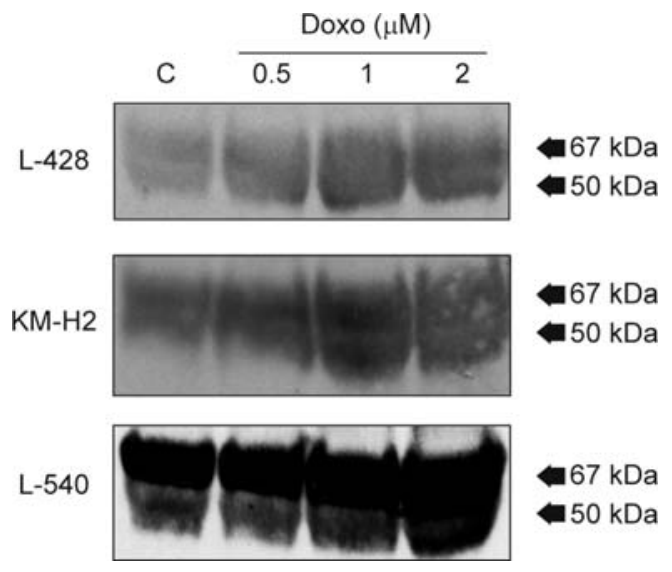

Figure 4. Doxorubicin up-regulates sCLU in HL cell lines in a dose-dependent fashion. Two bands are visible in the conditioned medium and the blurred appearance is due to the glycosilation of the secreted form.

negative (PET2-) patients have a favourable prognosis, though PET2-positive $\left(\mathrm{PET}^{+}\right)$patients have an unfavourable prognosis. Thus, we measured circulating clusterin levels at the time of diagnosis as well as after two ABVD chemotherapy cycles in order to evaluate any possible correlation with PET2 negativity or positivity (Fig. 5A). As summarized in Table I, PET2 patients exhibit decreased or steady clusterin in the serum compared to the value at the time of diagnosis. On the other hand, 7/9 PET2 $2^{+}$patients are characterized by increased circulating clusterin compared to the value at the time of diagnosis (Fig. 5A, lower panel). Despite the small number of samples tested, the differences in circulating clusterin of $\mathrm{PET}_{2}{ }^{+}$patients before and after two cycles of chemotherapy are statistically significant by paired t-test (Fig. 5B).

\section{Discussion}

HL is a unique disease where HRS tumoral cells are interspersed in a rich infiltrate of lymphocytes, eosinophils and fibroblasts, among others (3). The tumor microenvironment represented by the soluble cytokines and chemokines secreted by normal and neoplastic cells acting in a paracrine and an autocrine manner play a relevant role in the pathogenesis of this disease (3,31-33).

At variance with many tumors of epithelial origin, the expression and modulation of clusterin in lymphomas has been overlooked for many years. Immunohistochemical stainings performed by different groups reported HL samples to be negative for clusterin $(21,22)$, aside from a weak and occasional membranous or cytoplasmic positivity in HRS cells (22). Given the growing relevance of this protein in the research on cancer with respect to chemoresistance (34), we decided to revisit this issue and characterize clusterin expression in HL cell lines as a model for malignant lymphoid cells.

In the first part of our work we assess whether clusterin expression in HL-cell lines is affected by biologically relevant molecules like IFN- $\gamma$ and doxorubicin or by highdoses of IR. IFN- $\gamma$ is a Th- 1 cytokine produced and secreted
A

PET2 -

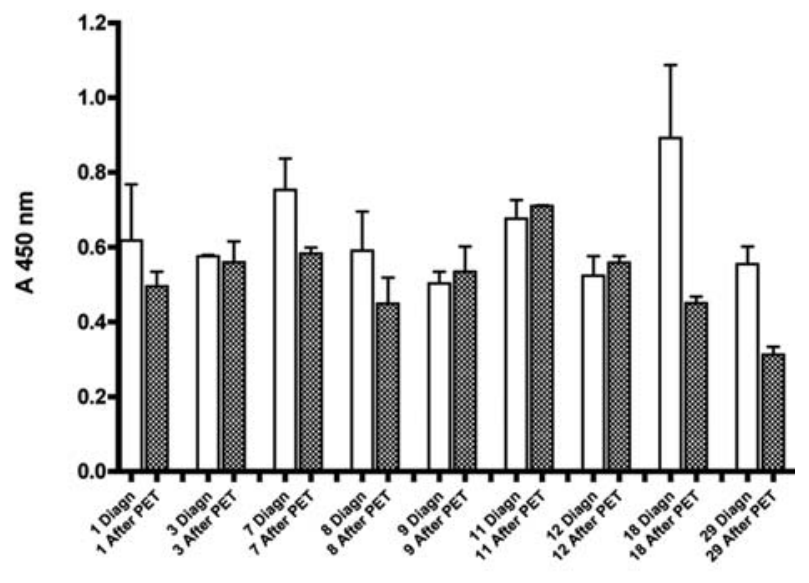

PET 2+

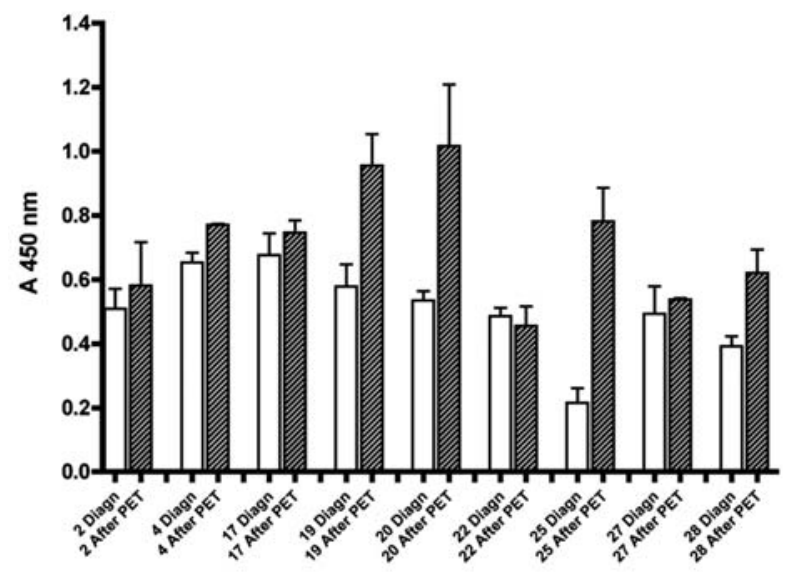

B

Circulating clusterin levels

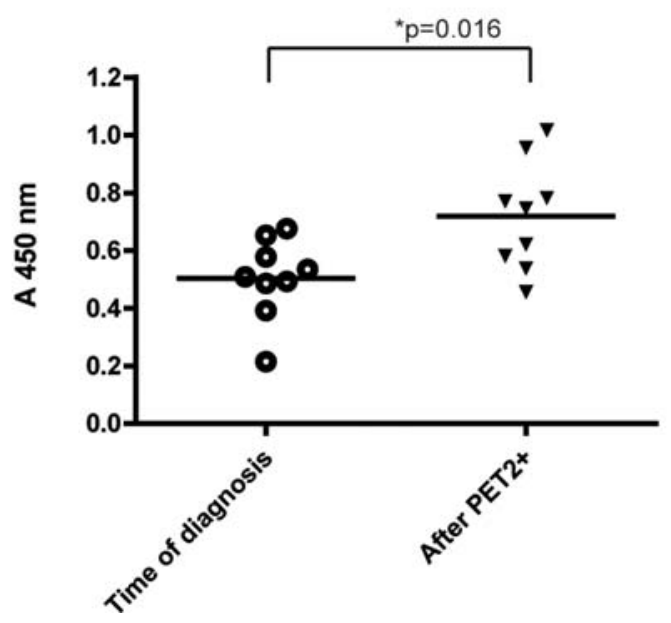

Figure 5. Circulating clusterin levels in HL patients. For each patient the histograms represent the levels in the sera at the time of diagnosis (empty bars) and after two cycles of chemotherapy followed by PET scan (filled bars). (A) Circulating levels in PET2- sera (9 patients, upper panel) and circulating levels in $\mathrm{PET}^{+}$sera (9 patients, lower panel). (B) Comparison of the circulating levels in $\mathrm{PET2}^{+}$sera. In the $\mathrm{PET}^{+}$patients the increase of circulating clusterin after two cycles of chemotherapy is significantly different compared to the levels at the time of diagnosis (paired t-test, $\mathrm{p}<0.05$ ). 
by $\mathrm{CD}^{+} \mathrm{T}$ cells and the manner in which the reactivation of $\mathrm{CD}^{+} \mathrm{T}$ cells is associated to IFN- $\gamma$ production in HL bulk tumors has recently been demonstrated (26). We investigated whether this cytokine could have any effect on intracellular clusterin and we found that the main isoforms of this protein are up-regulated, together with p53, after $24 \mathrm{~h}$ incubation. These changes are accompanied by the nucleosome release from the nucleus of the treated cells, suggesting therefore that IFN- $\gamma$ may have a pro-apoptotic activity on malignant lymphoid cells that has not yet been reported and therefore deserves further studies. We did not, however, see a clear antiproliferative effect mediated by this cytokine and this could potentially be explained by the fact that the activation of the p53 pathway is not strong enough. We next demonstrated how doxorubicin, a chemotherapeutic drug currently used for the first line of therapy of HL (ABVD) $(27,28)$, can up-regulate intracellular and secretory clusterin. The marked up-regulation of the intracellular isoforms of 80 and $55 \mathrm{kDa}$ occurs simultaneously with an increase in p53, in accordance to doxorubicin pro-apoptotic activity, showing that clusterin takes part in the drug-mediated response of HL cells. Thus, we investigated whether the same doxorubicin concentrations shown to induce intracellular clusterin also determine the increase of the secreted, glycosylated isoforms in the conditioned medium and we show the dose-dependent sCLU increase after $24 \mathrm{~h}$ in the three HL cell lines tested. This last observation suggests that, following chemotherapy, the HRS and, possibly the normal lymphocytes of the affected lymphnodes contribute to the levels of circulating clusterin.

Radiotherapy is an approach often used for consolidation therapy of HL $(7,8)$. X-rays are a relevant stimulus known to affect transcription factors and clusterin expression in breast and prostate cancer cells $(15,34,35)$. We show that, also in these lymphoid models, all the intracellular isoforms are up-regulated up to $72 \mathrm{~h}$ after a single X-ray dose of $12 \mathrm{~Gy}$. Consistently with the activation of the intrinsic apoptotic pathway (p53 and Bax up-regulation), clusterin expression is triggered by X-rays that cause direct DNA damage and reactive oxygen species-mediated damage and is therefore a hallmark of the surviving population.

Since we hypothesized that chemotherapy may affect in vivo sCLU levels, the last experiments were aimed at collecting preliminary data on the circulating clusterin in HL patients who had undergone two cycles of doxorubicincontaining chemotherapy (ABVD). The data on an initial group of 18 confirmed HL cases in which circulating clusterin levels were measured at the time of the diagnosis and after two cycles of chemotherapy followed by PET scan are reported here. We show a preliminary but intriguing association between circulating clusterin increase and PET2 positivity in 7 out of 9 patients. On the other hand, no association was observed in the 9 PET2- patients. As recently demonstrated, PET2 positivity is often associated to a poor outcome of HL patients $(30,36)$. This fact could be consistent with the described role of sCLU in chemoresistance (34). Indeed, several different variables and tissues determine the levels of circulating clusterin in vivo and it would therefore be informative to investigate a larger cohort of patients and to carefully analyze the results in order to characterize this correlation.
These data collectively demonstrate that clusterin is a stress-inducible protein in HL and that it takes part in the adaptive response of lymphoid cells to very different stimuli, including chemotherapeutic drugs and IR. Further experiments aimed at characterizing the existing molecular interactions, for instance, between intracellular clusterin and p53 and to define the possible role for sCLU in chemoresistance of lymphoid cells are currently being planned. The preliminary data collected on patients' sera also suggest that this glycoprotein is found in higher concentrations in blood from patients who have undergone two cycles of chemotherapy but still show a hypercaptating neoplastic mass. It would therefore be beneficial to increase the scale of the study to include a greater number of subjects in order to evaluate the potential of this putative new biomarker in HL.

\section{Acknowledgements}

This research was funded and supported by Gruppo Amici dell'Ematologia (GRADE) no profit association, Reggio Emilia, Italy.

\section{References}

1. Altekruse SF, Kosary CL, Krapcho M, Neyman N, Aminou R, Waldron W, Ruhl J, Howlader N, Tatalovich Z, Cho H, Mariotto A, Eisner MP, Lewis DR, Cronin K, Chen HS, Feuer EJ, Stinchcomb DG and Edwards BK (eds.): SEER Cancer Statistics Review, 1975-2007, National Cancer Institute. Bethesda, MD, http://seer.cancer.gov/csr/1975_2007/, based on November 2009 SEER data submission, posted to the SEER website, 2010.

2. Diehl V, Stein H, Hummel M, Zollinger R and Connors JM: Hodgkin's lymphoma: biology and treatment strategies for primary, refractory and relapsed disease. Hematology Am Soc Hematol Educ Program pp225-247, 2003.

3. Skinnider BF and Mak TW: The role of cytokines in classical Hodgkin lymphoma. Blood 99: 4283-4297, 2002.

4. Mathas S, Lietz A, Anagnostopoulos I, Hummel F, Wiesner B, Janz M, Jundt F, Hirsch B, Jöhrens-Leder K, Vornlocher HP, Bommert K, Stein H and Dörken B: c-FLIP mediates resistance of Hodgkin/Reed-Sternberg cells to death receptor-induced apoptosis. J Exp Med 199: 1041-1052, 2004.

5. Canellos GP, Abramson JS, Fisher DC and Lacasce AS: Treatment of favorable, limited-stage Hodgkin's lymphoma with chemotherapy without consolidation by radiation therapy. J Clin Oncol 28: 1611-1615, 2010.

6. Gobbi PG, Rosti V, Valentino F, Bonetti E, Merli F, Stelitano C, Dondi A, Quarta G, Falorio S and Federico M: The early- and intermediate-term toxicity to primitive hematopoietic progenitor cells of three chemotherapy regimens for advanced Hodgkin lymphoma. Clin Lymphoma Myeloma 9: 425-429, 2009.

7. Girinsky $\mathrm{T}$ and Ghalibafian M: Radiotherapy of Hodgkin lymphoma: indications, new fields, and techniques. Semin Radiat Oncol 17: 206-222, 2007.

8. Punnett A, Tsang RW and Hodgson DC: Hodgkin lymphoma across the age spectrum: epidemiology, therapy, and late effects. Semin Radiat Oncol 20: 30-44, 2010.

9. Shannan B, Seifert M, Boothman DA, Tilgen W and Reichrath J: Clusterin and DNA repair: a new function in cancer for a key player in apoptosis and cell cycle control. J Mol Hist 37: 183-188, 2006.

10. Shannan B, Seifert M, Leskov K, Willis J, Boothman D, Tilgen W and Reichrath J: Challenge and promise: roles for clusterin in pathogenesis, progression and therapy of cancer. Cell Death Differ 13: 12-19, 2006

11. Scaltriti M, Santamaria A, Paciucci R and Bettuzzi S: Intracellular clusterin induces G2-M phase arrest and cell death in PC-3 prostate cancer cells. Cancer Res 64: 6174-6182, 2004.

12. Rizzi F and Bettuzzi S: Targeting clusterin in prostate cancer. Journal Physiol Pharmacol 59: 265-274, 2008.

13. Pucci S, Bonanno E, Picchiorri F, Angeloni C and Spagnoli LG: Modulation of different clusterin isoforms in human colon tumorigenesis. Oncogene 23: 2298-2304, 2004. 
14. Mazzarelli P, Pucci S and Spagnoli LG: CLU and colon cancer. The dual face of CLU: from normal to malignant phenotype. Adv Cancer Res 105: 45-61, 2009.

15. Yang CR, Leskov K, Hosley-Eberlein K, Criswell T, Pink JJ, Kinsella TJ and Boothman DA: Nuclear clusterin/XIP8, an $\mathrm{X}$-ray-induced $\mathrm{Ku} 70$-binding protein that signals cell death. Proc Natl Acad Sci 97: 5907-5912, 2000.

16. Toffanin S, Daidone MG, Miodini P, De Cecco L, Gandellini P and Cappelletti V: Clusterin: a potential target for improving response to antiestrogens. Int J Oncol 33: 791-798, 2008.

17. Albert JM, Gonzalez A, Massion PP, Chen H, Olson SJ, Shyr Y, Diaz R, Lambright ES, Sandler A, Carbone DP, Putnam JB Jr, Johnson DH and Lu B: Cytoplasmic clusterin expression is associated with longer survival in patients with resected non small cell lung cancer. Cancer Epidemiol Biomarkers Prev 16: 1845-1851, 2007.

18. Chou TY, Chen WC, Lee AC, Hung SM, Shih NY and Chen MY Clusterin silencing in human lung adenocarcinoma cells induces a mesenchymal-to-epithelial transition through modulating the ERK/Slug pathway. Cell Signal 21: 704-711, 2009.

19. Chi KN, Eisenhauer E, Fazli L, Jones EC, Goldenberg SL, Powers J, Tu D and Gleave ME: A phase I pharmacokinetic and pharmacodynamic study of OGX-011, a 2'-methoxyethyl antisense oligonucleotide to clusterin, in patients with localized prostate cancer. J Natl Cancer Inst 97: 1287-1296, 2005.

20. Zoubeidi A, Chi K and Gleave M: Targeting the cytoprotective chaperone, clusterin, for treatment of advanced cancer. Clin Cancer Res 16: 1088-1093, 2010.

21. Wellmann A, Thieblemont C, Pittaluga S, Sakai A, Jaffe ES, Siebert P and Raffeld M: Detection of differerntially expressed genes in lymphomas using cDNA arrays: identification of clusterin as a new diagnostic marker for anaplastic large-cell lympohomas. Blood 96: 398-404, 2000.

22. Nascimento AF, Pinkus JL and Pinkus GS: Clusterin, a marker for anaplastic large cell lymphoma. Am J Clin Pathol 121: 709-717, 2004.

23. Chandra P, Plaza JA, Zuo Z, Diwan AH, Koeppen H, Duvic M, Medeiros LJ and Prieto VG: Clusterin expression correlates with stage and presence of large cells in mycosis fungoides. Am J Clin Pathol 131: 511-515, 2009

24. Marshall NA, Christie LE, Munro LR, Culligan DJ, Johnston PW, Barker RN and Vickers MA: Immunosuppressive regulatory $\mathrm{T}$ cells are abundant in the reactive lymphocytes of Hodgkin lymphoma. Blood 103: 1755-1762, 2004.

25. Cozen W, Gill PS, Salam MT, Nieters A, Masood R, Cockburn MG, Gauderman WJ, Martínez-Maza O, Nathwani BN, Pike MC, Van Den Berg DJ, Hamilton AS, Deapen DM and Mack TM: Interleukin-2, interleukin-12, and interferon-gamma levels and risk of young adult Hodgkin lymphoma. Blood 111: 3377-3382, 2008.
26. Yamamoto R, Nishikori M, Kitawaki T, Sakai T, Hishizawa M, Tashima M, Kondo T, Ohmori K, Kurata M, Hayashi T and Uchiyama T: PD-1-PD-1 ligand interaction contributes to immunosuppressive microenvironment of Hodgkin lymphoma. Blood 111: 3220-3224, 2008.

27. Bartlett NL: Modern treatment of Hodgkin lymphoma. Curr Opin Hematol 15: 408-414, 2008.

28. Carver JR, Schuster SJ and Glick JH: Doxorubicin cardiotoxicity in the elderly: Old drugs and new opportunities. J Clin Oncol 26: 3122-3124, 2008.

29. Rizzi F and Bettuzzi S: The clusterin paradigm in prostate and breast carcinogenesis. Endocrine-Related Cancer 17: R1-R17, 2010 .

30. Gallamini A, Hutchings M, Rigacci L, Specht L, Merli F, Hansen M, Patti C, Loft A, Di Raimondo F, D'Amore F, Biggi A, Vitolo U, Stelitano C, Sancetta R, Trentin L, Luminari S, Iannitto E, Viviani S, Pierri I and Levis A: Early interim 2(18F)fluoro-2-deoxy-D-glucose positron emission tomography is prognostically superior to international prognostic score in advanced-stage Hodgkin's lymphoma: a report from a joint Italian-Danish study. J Clin Oncol 25: 3746-3752, 2007.

31. Carbone A, Gloghini A, Cabras A and Elia G: Differentiating germinal center-derived lymphomas through their cellular microenvironment. Am J Hematol 84: 435-438, 2009.

32. Aldinucci D, Poletto D, Gloghini A, Nanni P, Degan M, Perin T, Ceolin P, Rossi FM, Gattei V, Carbone A and Pinto A: Expression of functional interleukin-3 receptors on Hodgkin and Reed-Sternberg cells. Am J Pathol 160: 585-596, 2002.

33. Aldinucci D, Lorenzon D, Cattaruzza L, Pinto A, Gloghini A, Carbone A and Colombatti A: Expression of CCR5 receptors on Reed-Sternberg cells and Hodgkin lymphoma cell lines: involvement of CCL5/Rantes in tumor cell growth and microenvironmental interactions. Int J Cancer 122: 769-776, 2008.

34. Djeu JY and Wei S: Clusterin and chemoresistance. Adv Cancer Res 105: 77-92, 2009.

35. Criswell T, Leskov K, Miyamoto S, Luo G and Boothman DA: Transcription factors activated in mammalian cells after clinically relevant doses of ionizing radiation. Oncogene 22: 5813-5827, 2003

36. Castagna L, Bramanti S, Balzarotti M, Sarina B, Todisco E, Anastasia A, Magagnoli M, Mazza R, Nozza A, Giordano L, Rodari M, Rinifilo E, Chiti A and Santoro A: Predictive value of early $18 \mathrm{~F}$-fluorodeoxyglucose positron emission tomography (FDG-PET) during salvage chemotherapy in relapsing/ refractory Hodgkin lymphoma (HL) treated with high-dose chemotherapy. Br J Haematol 145: 369-372, 2009. 